\title{
ORIENTplus: The super highway for R\&E collaboration between Europe and China
}

\author{
Jennifer An \\ China Education and Research Network \\ FIT Building Tsinghua University Beijing, China \\ E-mail: anjie@cernet. edu. cn
}

\section{Jiangning Chen}

China Science and Technology Network

4 Zhongguancun Nansijie Haidian Distric Beijing, China

E-mail: cjnecstnet. cn

In the workshop, we gave the introduction on ORIENTplus project.

\begin{abstract}
ORIENTplus is a high capacity e-infrastructure linking European and Chinese researchers. It connects the Chinese national research and education networks (NRENs) CERNET and CSTNET to the 40 million users of the pan-European GÉANT network via a trans-Siberian link between Beijing and London. Jointly funded by the European Union, European and Chinese NRENs until the end of 2014 it provides the highest capacity connection and the shortest network path between the two regions. ORIENTplus underpins over 25 data intensive collaborations including participation in the Large Hadron Collider study, the ITER global energy fusion programme, projects at the Shanghai Astronomical Observatory, genome research and the ARGO-YBJ cosmic ray observation initiative. ORIENTplus is a joint project of CERNET (China Education and Research Network) CSTNet (China Science and Technology Network) and the European research and education networking community and is co-ordinated by research networking organisation DANTE.
\end{abstract}

e-Infrastructures for e-Sciences 2013 A CHAIN-REDS Workshop organised under the aegis of the European Commission (eIeS 2013)

October 22, 2013

Beijing, P.R. of China 


\section{ORIENTplus Introduction}

ORIENTplus project was sponsored by the European Commission, Chinese Government and the partner in Chinese and European NRENs. Project period is from 2011-2014. Project partners on China side: CERNET and CSTNET; on Europe side: European NRENs and Dante as the project coordinator. Total Budget was 4 million euro. The aim of ORIENTplus is to continue a direct link between China and Europe for R\&E, increase its speed, to stimulate further development of services and promote the use of the services.

Timeline for ORIENTplus link: in 2011, the link is from Copenhagen to Beijing at 2.5G (CERNET, supplied by TeliaSonera); in 2012, the link is from London to Beijing at $2.5 \mathrm{G}$ (CSTNET, supplied by China Unicom as result of tender); from 2013 to 2014, the link is from London to Beijing at 10G (EU partners, supplied by China Unicom as result of tender).

The brief introduction on CERNET. CERNET is the biggest NREN in China, it has fiber netwok backbone at $100 \mathrm{G}(40 \lambda)$ and reaches 31 provinces and over 200 cities, CERNET totally has 38 PoPs connect more than 200 universities. The brief introduction on CSTNET. CSTNET is the science and technology network in China, and its backbone at 10G and has 12 branches all around China, and it connect 100+ institutes in China Academy of Sciences.

Then a technical view on ORIENTplus: the current $10 \mathrm{G}$ connction is from London OLE to Beijing 6IX. Half of the capacity is for routing using, and the other 5G is for lightpath connection for some specific applications end to end using. ORIENTplus provide mutual backup with another international R\&E network collaberation project from Beijing to Los Angeles. By providing reciprocal backup services via two $10 \mathrm{Gbps}$ connections around the globe, the organisations involved will maximise connectivity and provide a stronger, more resilient service to researchers as they work together on major projects and share growing volumes of data.

\section{ORIENTplus applications}

Over 25 substantial scientific and educational collaborative projects and programmes are using the ORIENTplus link. Following is the application example:

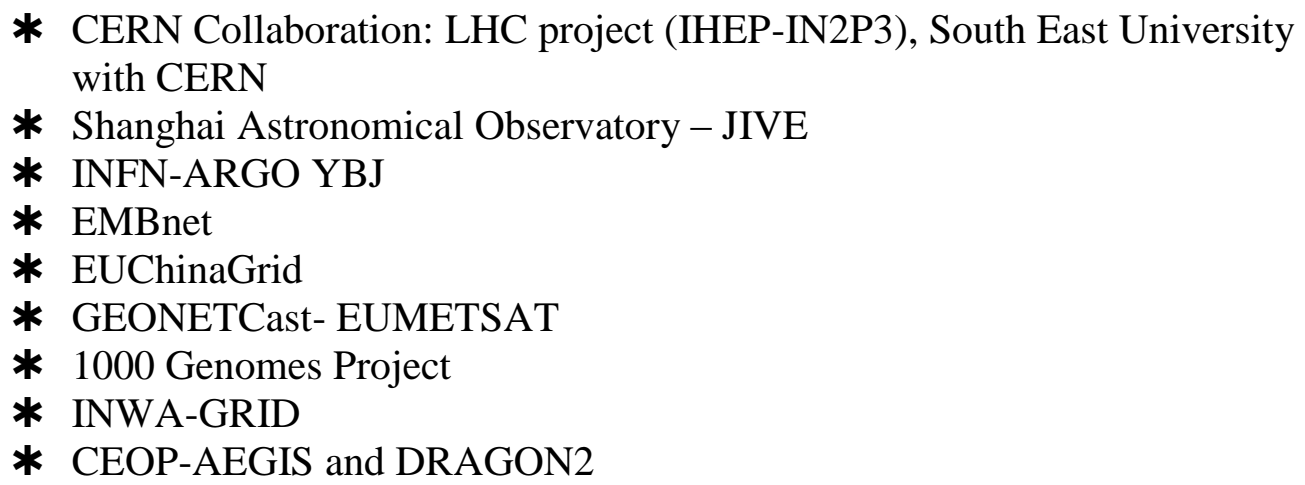


* Shanghai Jiao Tong University - University of Essex

* Bridge-Grid

* ITER - the global fusion energy programme

* Global atmospheric research, remote robotic experiments, etc.

\section{References}

